\title{
Factors in the Decision-Making of North Carolina Probation Officers
}

\author{
JOHN P. RHFD \\ Associate Professor, Department of Sociology. Jacksonville University \\ Assistant Professor, Department of Sociology, University of North Carolina, 1963-64; \\ Research Analyst, Institute of Government, University of North Carolina, 1964-65 \\ B.A. (Sociology), 1947, Tulane University; M.A. (Sociology), 1950, LL..B., 1953. \\ University of Illinois; Ph.D. (Sociology), 1964, Louisiana State University \\ Charles E. Kinc; \\ Professor, Department of Sociology, North Carolina College \\ Associate Professor, Department of Sociology, Allen University, 1941-45: \\ Professor, Department of Sociology, Bennett College. 1949.51 \\ B.A., 1997, Paine College; M.A. (Sociology), 1940, Iniversity of Mlichigan; \\ Ph.D. (Sociology), 1950, University of Chicago \\ A questionnaive on eight revocation cases selected from state \\ files revealed some discemible differences in decisions and ra- \\ tionalizations anong 108 freld officers of the North Carolina \\ Probation I) partment. Lambda and $Q$ measuves of cross-tabu- \\ lated characteristics of the offerers, decisions, and rationalizations \\ showed that values tended to concentrate in cases characterized \\ by a rezoking pattern or extenuating circumstances and in case \\ situations where the police or courts were holding the proba- \\ lioner or acting upon his violation. Most officers gave offecer. \\ oriented or social order reasons for their decisions rather than \\ reasoms that were probationer-oriented.
}

$\mathrm{D}$

ECISION-MAKING has been the concern of a number of recent publications.' The treatment accorded it has usually been in terms of levels, processes, and factors which have ranged from group size, pressures, and leadership to psychological and ethical values. Whatever the treatment, however, the focus has generally been on relatively highstatus performers and law-abiding behavior.

1 GIendon Schubett. ed.. Judicial DerisionMaking (Glencuc. Ill.: Free Press, 1963); Paul Wasserman and Fred S. Silander. Decision-Mak. ing, An Annolated Bibliogruphy (Ithaca. N. Y': Graduate School of Business and Public Administration, Corncll University. 1958).
This paper is concerned with decision-making lactors. Unlike other publications, the following discussion makes use of written cases and focuses on the probation officer and his choice of decisional alternatives. Factors operative in the decisions of law enforcement officers are generally of an unknown quality. Except for studies of judicial decisionmaking, the literature in this area consists of inspirational messages, bread-anclbutter complaints of low wages and heavy caseloads, and polemics for up. grading the service.:

\footnotetext{
E Don C. Cibbons, Changing the l.an'bleake (Englewood Cliffs. X. J.: Prentice-Hall. 1965) pp. 220-21.
} 


\section{Design and Population}

The questionnaire we devised and administered to North Carolina probation officers consisted of eight cases randomly selected from the files of the North Carolina Probation Department, a cover sheet, and the Eysenck-Nagle "Survey of Opinion." 3 Each case selected was digested, condensed, and presented in the same manner. The format included a fact situation, background characteristics of the probationer, his current violation, decisional summaries, and a multiple choice question which confronted the probation officer with decisional alternatives for each of four different case situations-(1) when the officer alone knew of the violation; (2) when a reliable party told him of the violation; (3) when the police were holding probationer for the violation; and (4) when the judge asked the officer for a recommendation in the hearing of the violation. In each case situation the probation officer was to select the decisional alternative that best represented what he would do-given the facts, background characteristics of the probation$e r$, and the probation violation in question. Decisional alternatives and case situations were followed by a question which asked the officer to explain briefly why he had chosen a particular alternative in each situation.

\section{STRATEgies and Response}

The questionnaire was administered to 108 field officers in May and June of 1965 , during their annual in-service training program at the Institute of Government in Chapel Hill, N. C. All materials were presented de novo; there was no mention that all cases were rewritten revocations from the files of the probation department. Under these circumstances an atmosphere was created for a firsthand study of decision-making, with confidentiality of information promised to those who participated.

3 Stuart C. Nagel. "Off-the-Bench Judicial Attitudes," Judicial Decision-Making. Schubert. supra note 1, pp. 29-53.

\section{Factors and Decisions}

One of the assumptions we made in developing the questionnaire was that certain factors were more significant than others in the probation officers' decisions and rationalizations about decisions. These factors were sex, race, college major, role played, age-crime type preferred, average monthly caseload, revocations, previous employment, organizational memberships, residence, and liberalism-conservatism. It was thought that these "background characteristics" would differentiate officer decisions and rationalizations sufficiently to contribute to a growing body of "revelation research" in the law enforcement field.

For the sake of convenience in treat. ing the data, categorizations and protocols were adopted. Among these were classifications of officer choices of action as "unofficial" (U), "official" (O), and "revocation" (R). "Unofficial" meant that the officer would handle the violation himself rather than go through official agencies or channels. Where official channels or agencies were resorted to, the choice of action was categorized as "official" or "revocation." Decisons were then cross-tabulated with characteristics of the case and the case situation in order to facilitate presentation and interpretation of the data.

Officer rationalizations for choice of action were similarly handled. These "reasons why" were classified as being oriented toward the probationer $(P)$, the probation officer $(\mathrm{PO})$, or the social order (SO). The first of these meant that the alternative chosen was rationalized as being in the best interest of the probationer. Rationalizations that were officer-oriented reflected the officer's inability to cope with or do anything more for the probationer, or the need for more information on which to base a decision. Rationalizations oriented toward the social order were likely to stress the probationer's criminal behavior or his behavior in violating probation and its effects on others. 
TABLE I

Choice of action and Rational Supports by Case and (iharacteristics of North Carolina Probation Officers (Lambda Measures)

\begin{tabular}{|c|c|c|c|c|c|c|c|c|c|c|c|c|c|c|}
\hline \multirow[t]{2}{*}{ Characteristics } & Case 1 & \multicolumn{2}{|c|}{ Case 2} & \multicolumn{2}{|c|}{ Case 3} & \multirow{2}{*}{$\frac{\text { Case } 4}{\text { CA RS }}$} & \multicolumn{2}{|c|}{ Case 5} & \multicolumn{2}{|c|}{ Case 6} & \multicolumn{2}{|c|}{ Case 7} & \multicolumn{2}{|c|}{ Case 8} \\
\hline & CA RS & CA & RS & CA & RS & & $\mathrm{CA}$ & RS & C.A & RS & C.A & RS & C.A & RS \\
\hline \multicolumn{15}{|l|}{ College } \\
\hline Major & .07 & & .03 & .05 & .08 & .05 & .01 & .11 & (0) & .03 & & & .01 & \\
\hline \multicolumn{15}{|l|}{ Roles You } \\
\hline Play & .02 & .10 & .01 & .12 & .11 & & .06 & .10 & .04 & .10 & & & & \\
\hline Sex & & .02 & & .08 & .07 & .05 & & .02 & .05 & .03 & & & & \\
\hline \multicolumn{15}{|l|}{ Age-Crime } \\
\hline Type & .03 & & .02 & .02 & .15 & & .02 & .08 & .09 & .10 & .07 & & $.11 \prime$ & 07 \\
\hline Race & & .02 & .04 & .03 & .05 & & & .01 & .03 & .02 & & .04 & & \\
\hline \multicolumn{15}{|l|}{ Av. Monthly } \\
\hline Caseload & & & .02 & .01 & .01 & .04 & .08 & & .08 & & & & & \\
\hline Scores & .18 & & .22 & .04 & .12 & $.18 \quad .18$ & .04 & .20 & .02 & .18 & & .17 & .01 & .13 \\
\hline Revocations & .02 & & .11 & .12 & .09 & .01 & .05 & .09 & .07 & .06 & .03 & & .05 & \\
\hline Memberships & & & & .01 & .03 & & & .05 & .05 & .08 & & & & \\
\hline \multicolumn{15}{|l|}{ Previous } \\
\hline Employment & & & .03 & .03 & .13 & & & .10 & .05 & .06 & & & .05 & \\
\hline
\end{tabular}

Applying Lambda measures to crosstabulated data, however, failed to reveal consistent relationships. In crosstabulations by the case, roles ${ }^{4}$ and scores" produced the highest values, and number of organizational memberships the fewest. Concentrations of values appeared in Cases 2, 3, 5, and 6. In each there had been, before the violation which causes the revocation, a number of minor infractions by the probationer and warnings by the officer. Three of the four (Cases 2, 3, 6) involved sixteenyear-old males with good family backgrounds but with previous records of assault or automotive offenses. One (Case 5) was a 32-year-old male with an improper license plates offense. Three were white; one of the youngsters was a Negro. All four revoking violations occurred publicly or involved arrest or

\footnotetext{
4 Roles which the officer could sclect inclucle big brother, big sister, friend, policeman, man. ager, stranger, and Giond Samaritan. Most officers selected big brother or sister, fricnd. and man. ager roles: some selected multiple roles of hat no role preferences.

5 The median score for officers who answercel the Eysenck-Nagle "Survey of Opinion" was 113. All above were treated as liberal; all at 113 and belok: as conscrvative.
}

custody by police before the probation officer was aware of what had happened. Of the revoking violations, three were automotive and the fourth was a curfew violation.

This cluster of characteristics was not as much in evidence in Cases $1,4,7$, and 8 . For one thing, the probationers were generally older (eighteen, twenty-three, twenty-nine, forty-two) and two (Cases 7 and 8) had bad reputations. For another, the pattern of minor infractions, warnings, and public or official involvement because of the violation was not uniformly present. In Case l (driving recklessly and without a license) and Case 4 (absconding) there were no prior infractions or warnings. Infractions appeared in Case 7 but they occurred too close to the revoking violation (break. ing, entering, and larceny) for warnings. In Case 8 (nonsupport) police were not involved: the probationer had asked for and was given additional time to catch up on his support payments, and, when he failed to make the payments, the officer wals confronted with a multiple support violation.

Rational support (RS) values were generally more numerous and higher 
than values for choice of action (CA). Whether these variations in values were due to subjective bias in classifying reasons or simply differential responses is a moot question. If differential responses are implied, then even official handling and revocation may be rationalized contrary to reasonable expectations (i.e., for the probationer's benefit rather than for society's).

Relationships of choice of action and rational supports to the same factors were generally limited. Some exceptions were found in Cases 3 and 4 , where "roles" and "scores," respectively, pro. duced meaningful associations. In Case 3, "roles" produced associations of .12 (CA) and .11 (RS) with "big brother and sister" roles strongly in favor of "unofficial" action for "officer-oriented" reasons. Other roles preferred "official" action or "revocation" with "multiple" roles for "probationer-oriented" reasons and the remainder for reasons that were oriented either toward the officer or toward the social order. In Case 4 similar disharmonies were produced. "Scores" yielded values of .13 and .18, with "liberals" for "unofficial" and "conservatives" for "official" actions. The rationalizations for the action, how. ever, were mainly "officer-oriented" for the "liberals" and about evenly divided between "officer" and "social order" for the "conservatives."

Part of the explanation for the general lack of high values, relatedness of the same factors to choice of action and rational supports, and the inconsistency of decisions and reasons would seem to lie with the cases themselves. Purpose rather than randomness in the selection of cases from probation files might have enabled one to differentiate decisions and reasons on the basis of the charac. teristics that were used." As it turned out, the cases were not too dissimilar

\footnotetext{
6 Two immediate possibilities for better dif. ferentiation are graded violations and further refinement of the revoking pattern of minol infractions, warning. and public or police involvement of the last or revoling violation.
}

and the outcomes were rather limited in character. Apart from the cases, the geographical area has a conservative subculture. The conservativeness of the subculture is manifest in the liberalism scores of the officers and the rationlizations for the decisions they made. Officer scores ranged from 74 to 141 , with a median of 113 , for 108 officers who filled out the Eysenck-Nagle "Survey of Opinion." " If anything, the scores understate the conservatism of the officer because, unknown at the time, some of the icleas and areas of investigation were covered in in-service training sessions with the officers the year before the questionnaire ivas administered. Rationalizations, on the other hand, were predominantly social order- or officer-oriented. In only ten of 248 instances did 50 per cent or more of the officers rationalize decisions in terms of probationers.

\section{SrTiations AND DrCisions}

Another basic assumption was that, according to the siluation, officer decisions and rationalizations would vary. Each case, consequently, was broken down into four case situations which replicated the source and origin of officer knowleclge about probation violations. In brief, the situations were "you knew;" "party told you," "police were holding," and "judge asked." Inder this breakdown the officers made decisions and rationalizations in situations much as probation file materials suggested they !licl on the job. The results of these decisions and rationalizations in situations are presented as Lambda measures in Table 2.

Examination of the table indicate that meaningful associations were slight. ly greater than double those found in Table 1. In order of their effectiveness, scores, age-crime t!pe preferences, ${ }^{8}$ race, college major, ${ }^{9}$ caseload, ${ }^{10}$ and roles

i Nangle's median was 109 on a scate that ranged from 41 to 195 .

= The age-crime lopes from which the officers were to select those they preferred to supervise were the following: no preference, youthful 
TABLE 2

Choice of action and Rational Supports by Case, Situation, and Characteristics of North Carolina Probation Officers (Lambda Measures)

\begin{tabular}{|c|c|c|c|c|c|c|c|c|}
\hline & You & Knew & $\begin{array}{r}\text { Pa } \\
\text { Told }\end{array}$ & rty & & $\begin{array}{l}\text { lice } \\
\text { ere } \\
\text { ding }\end{array}$ & & $\begin{array}{l}\text { Idge } \\
\text { sked }\end{array}$ \\
\hline & UOR" & $\mathrm{PPOSO}^{\mathrm{b}}$ & $\overline{\text { UOR }}$ & PPOSO & $\overline{\text { UOR }}$ & PPOSO & UOR & PPOSO \\
\hline \multicolumn{9}{|l|}{ Case 1} \\
\hline $\begin{array}{l}\text { College Major } \\
\text { Roles You Play }\end{array}$ & & .04 & & & & & & .09 \\
\hline Sex & & .03 & & & & & & \\
\hline Age-Crime & & .11 & & & & & & .15 \\
\hline Race & & .05 & & & & & .40 & \\
\hline Av. Mo. Cases & & .03 & & & & & .04 & \\
\hline Scores & & .08 & & & & & & .10 \\
\hline Memberships & & .05 & & & & & & \\
\hline Revocations & & .08 & & & & & & \\
\hline \multicolumn{9}{|l|}{ Case 2} \\
\hline College Major & & & & & .08 & & & \\
\hline Roles You Play & .14 & & .08 & & .20 & & & \\
\hline Sex & & $\therefore \therefore$ & & & .05 & & $\ldots$ & \\
\hline Age-Crime & .11 & .02 & & & .09 & & & .02 \\
\hline \multicolumn{9}{|l|}{ Race } \\
\hline Av. Mo. Cases & .02 & . & & & .02 & .03 & & \\
\hline Scores & & $\therefore$ & $\because$ & $\therefore:$ & .02 & .06 & & .02 \\
\hline Memberships & $\because$ & & 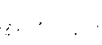 & & & & & \\
\hline Revocations & & 2 & & & .05 & & & \\
\hline \multicolumn{9}{|l|}{ Case 3} \\
\hline College Major & .11 & .04 & & & .05 & & & .08 \\
\hline Roles You Play & .16 & & .11 & & & & & \\
\hline Sex & .07 & .04 & & & & & & .10 \\
\hline Age-Crime & .09 & .19 & & & & & & .18 \\
\hline Race & & & & & & & -.25 & .05 \\
\hline Av. Mo. Cases & .09 & & & .04 & .06 & & & .05 \\
\hline Scores & .11 & & & & & & & .10 \\
\hline Memberships & .07 & & & & & & & \\
\hline Revocations & .04 & & & & & & & .06 \\
\hline \multicolumn{9}{|l|}{ Case 4} \\
\hline $\begin{array}{l}\text { College Major } \\
\text { Roles You Play }\end{array}$ & .22 & & .11 & & & & & .11 \\
\hline Sex & .08 & & & & & & & \\
\hline Age-Crime & & & & & & & & .02 \\
\hline Race & & & & & & & .27 & \\
\hline Av. Mo. Cases & .10 & & .16 & .04 & & & & .02 \\
\hline Scores & .34 & & .28 & & & .40 & & .07 \\
\hline Memberships & .07 & & & & & & & \\
\hline Revocations & .05 & & .04 & & & & & \\
\hline
\end{tabular}

- Choice of action as Unofficial, Official, or Rerocation.

- Rationalization for choice of action classified as oriented toward the Probationer, the Probation Officer, or the Social Order. 
TABLE 2

(Continued)

Choice of action and Rational Supports by Case, Situation, and Characteristics of North Carolina Probation Officers (Lambda Measlres)

\begin{tabular}{|c|c|c|c|}
\hline You Knew & $\begin{array}{c}\text { Party } \\
\text { Told You }\end{array}$ & $\begin{array}{c}\text { Police } \\
\text { Were } \\
\text { Holding }\end{array}$ & $\begin{array}{l}\text { Judge } \\
\text { Asked }\end{array}$ \\
\hline$\overline{\mathrm{OSO}^{\mathrm{b}}}$ & $\overline{\text { UOR PPOSO }}$ & $\overline{\text { UOR PPOSO }}$ & $\overline{\text { UOR PPOSO }}$ \\
\hline
\end{tabular}

Case 5

College Major

Roles You Play

Sex

Age-Crime

Race

Av. Mo. Cases

Scores

Memberships

Revocations

\section{Case 6}

College Major

Roles You Play

Sex

Age-Crime

Race

Av. Mo. Cases

Scores

Memberships

Revocations

\section{Case 7}

College Major

Roles You Play

Sex

Age-Crime

Race

Ar. Mo. Cases

Scores

Memberships

Revocations

\section{Case 8}

College Major

.08

.04

.02

.11

.07

.02

.06

.02

.05

.05

.07

.07

.03

.09
.09

.05

$\begin{array}{rrrr} & & & .05 \\ & & .16 & .10 \\ & & -.46 & .02 \\ .13 & .04 & & \\ & .10 & & .02\end{array}$

$.0 x$

.02

$.29 \quad .04$

.12

.18

.02

Roles You Play

Sex

Age-Crime

Cases

.02

.16

$.10 \quad .04$

.11

.02

.14
.02
.02

.03

.16

.09

.09

$-.62$

.03

.01

$.13 \quad .02$

Race

16

.18
.03
.05
.11
.01
.09

Memberships

Revocations

- Choice of action as Linofficial, Official, or Revocation.

- Rationalization for choice of action classified as oriented toward the Probationer, the Probation Officer, or the Social Order. 
produced the greatest number as well as the highest values, while memberships again. produced the fewest. Of the case situations, "you knew" and "judge asked" were the most volatile, with the latter alone accounting for twenty-one of forty-six associations of consequence. Case volatility in Table 2 , however, was dissimilar from that in Table 1 . In Table 2, Cases $3,4,5,7$, and 8 were the most fruitful, while the remainder were relatively weak in generating meaningful associations. In volatile cases, most of the meaningful associations were decisional rather than rationalizational.

Decisions and situations deserve some additional attention because, despite the generally mild nature of the cases, the values indicate that officers make decisions in situations that vary according to their background characteristics. In instances where values were produced the variations were in rather discernible directions. Liberals, no and multiple agecrime type preferences, big brother and sister roles, Negroes, and social science majors were more likely to be for "unoffcial" action and against "revocation" than their officer counterparts. If one pursues the differences situationally, the variations become even more pronounced. Moving from private and semi. private involvement of the violations to police and court involvement gives rise not only to more values but to values of

property offender, adult property offender, youthful sex offender, adult sex offender, youthful alcoholic, adult alcoholic, youthful motor vehicle offender, adult motor vehicle offender. and multiple age-crime types. Only four, how' ever, were usable because of the pronounced avoidance of sex, alcohol, and motor vehicle types.

- Social science, education, and business. ad. ministration comprised the usable college major categories.

10 Average monthly caseload gave mixed results. Sometimes the "minimum" and sometimes the "moderate" and "maximum" loads diverted from "revocation" or "official" action. The cxplanation would seem to lie in the departmental practice of assigning lighter loads to newer officers.

\section{TABLE 3}

Association of Residency, Scores, Choice of Action, aNd Rational SUPPORTS (Q Measures)

\begin{tabular}{|c|c|c|c|c|c|c|}
\hline \multirow[b]{2}{*}{ RURS } & \multicolumn{3}{|c|}{ Choice of Action } & \multicolumn{3}{|c|}{ Rational Supports } \\
\hline & $\bar{U}$ & $\mathrm{O}$ & $\mathbf{R}$ & $\mathbf{P}$ & PO & \\
\hline Case 1 & .17 & .23 & $\overline{1.00}$ & 4 & - & \\
\hline Case 2 & - & 一 & .27 & 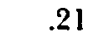 & - & \\
\hline Case 3 & .22 & .27 & .22 & .13 & .39 & \\
\hline Case 4 & .14 & - & 1.00 & .47 & - & \\
\hline Case 5 & 一 & .48 & .15 & .14 & 一 & \\
\hline Case 6 & .13 & .33 & .14 & .60 & .92 & \\
\hline Case 7 & .22 & - & .28 & - & .55 & \\
\hline Case 8 & .45 & .35 & - & .22 & .49 & \\
\hline
\end{tabular}

- Rural-urban residence and scores.

greater intensity. In other words, with these cases and characteristics the officers are best differentiated at points of maximum exposure to official agencies and process.

\section{Residency, SCOREs, AND Decisions}

Perhaps the best results were achieved by combining selected factors with decisions and supports. Application of $Q$ measures to residency ${ }^{11}$ and scores illustrates this approach, which produced meaningful associations in all cases and situations. With some exceptions, the patterns and interpretations noted in Tables 1 and 2 are applicable to Tables 3 and 4. The exceptions in Table 3 are to be found in Cases 1,4 , and 8 , and relate to the explicitness of the revoking patterns or to extenuating circum. stances. In Case 1 (reckless driving and without a license) and Case 4 (absconding), public or police involvement in the last or revoking violation occurred but prior infractions and warnings were absent. These three cases dealt with minority (1), affliction (4), 12 or an essentially noncriminal violation (8).

\footnotetext{
in Residency catcgories of rural and urban were based on the cover sheet question of "place of longest residence" which it was thought better reflected the molding milieu of officer attitudes and values than place of birth.

12 In Case 4 probationer was retarded.
} 
TABLE 4

Association of Residency, Scores, and Decisions gy Case and Situation (Q Measures)

\begin{tabular}{|c|c|c|c|c|c|c|c|c|c|c|c|c|}
\hline \multirow[b]{2}{*}{ RURS } & \multicolumn{3}{|c|}{ You Knew } & \multicolumn{3}{|c|}{$\begin{array}{l}\text { Party Told } \\
\text { You }\end{array}$} & \multicolumn{3}{|c|}{$\begin{array}{l}\text { Police Were } \\
\text { Holding }\end{array}$} & \multicolumn{3}{|c|}{ Judge Asked } \\
\hline & U & 0 & $\mathbf{R}$ & $U$ & $\mathrm{O}$ & $\overline{\mathbf{R}}$ & $\overline{\mathrm{u}}$ & o & $\mathbf{R}$ & $\mathrm{U}$ & O & $\bar{R}$ \\
\hline$\overline{\text { Case } 1}$ & .13 & .47 & - & - & .75 & - & - & .50 & - & .18 & - & - \\
\hline Case 2 & - & .12 & .34 & - & .33 & .30 & .18 & .11 & .42 & - & .23 & .15 \\
\hline Case 3 & .18 & .17 & .12 & .40 & .78 & .36 & - & .25 & .24 & .11 & .56 & .20 \\
\hline Case 4 & .18 & - & - & - & - & - & .28 & .10 & - & .21 & .17 & - \\
\hline Case 5 & .22 & - & .11 & .16 & .77 & - & .15 & .61 & .14 & .58 & .23 & .43 \\
\hline Case 6 & .22 & .19 & - & .21 & .26 & .33 & - & .80 & - & - & - & .16 \\
\hline Case 7 & .55 & - & .26 & .15 & - & .29 & - & - & .31 & - & - & .25 \\
\hline Case 8 & .74 & - & .33 & .49 & - & - & .32 & .23 & .23 & .84 & .74 & .17 \\
\hline
\end{tabular}

In Tables 3 and 4, residency had the effect of further differentiating the conservative and liberal elements in the officer population. "Rurals" were consistently less for "unofficial" action than "urbans" and markedly so if they had conservative scores. Urban liberals, on the other hand, exceeded all other combinations in being for "unofficial" action and expectedly against "revocation" in instances involving the revoking pattern, extenuating circumstances, and points of exposure to official agencies or processes.

Other combinations-roles and scores; and residency, scores, and rational supports-also proved effective. The latter, like decisional outcome, suggests a continuum, with conservative rurals at one end and urban liberals at the other. Rationalizations of the conservative ru. rals were predominantly "social order." or "officer-oriented," in contrast with urban liberals, who were "probationeroriented." Roles and scores provided meaningful associations when role categories were rotated against each other and conservative and liberal scores.

\section{Summary and Conclusions}

Despite case and officer homogeneity, some rather pronounced differences were encountered in decisions and ra. tionalizations in written cases by a group of 108 North Carolina probation officers. Both decisions and rationalizations, however, tended to vary by the case and the case situations devised for the study. In Cases 2, 3, 5, and 6, existence of a revoking pattern generated some of the more meaningful associations between roles played in supervision, scores, and decisions and rationalizations by the probation officers. Big brother and sister roles preferred "unofficial" action for "probationer-" or "officer-oriented" reasons to "official" action or "revocation" by friends and managers who gave "social order-" or "officer-oriented" reasons for their decisions. As determined by scores (based on the Eysenck-Nagle "Survey of Opinion"), liberals and conservatives were similarly split for much the same reasons. In case situations, police or court involvement with the violation produced more and higher values than private or semiprivate involvement. Situational values were primarily decisional and were obtained, for the most part, in cases where the revoking pattern was found. The exceptions occurred in instances of extenuating circumstances of minority, affliction, or technical violation of probation.

All of this suggests that exposuredisruption of private or semiprivate supervisory practice by intervening public, police, or court involvement in the casemay well be the key to differentiating 
the officer population. Social science majors, liberals, no and multiple agecrime type preferences, Negroes, and big brother and sister roles are more likely to be in favor of nonrevoking types of action than officers with other characteristics.
Of all the factors used, the officer's place of longest residence and scores produced the best results. $Q$ measures of this combination of factors indicated a continuum of decisons and rationalizations with the rural conservative at one end and the urban liberal at the other. 